\title{
Measurement of urinary kidney injury molecule-1 as a predictive biomarker of contrast-induced acute kidney injury
}

\author{
Fadhil Jawad Al-Tu'ma, ${ }^{a}$ Maha Hamood Dheyauldeen, ${ }^{*}$ and Ryiadh Mohi Al-Saegh ${ }^{b}$
}

\author{
Department of Biochemistry, College of Medicine, University of Kerbala, Iraq. \\ bDepartment of Nephrology, College of Medicine, University of Kerbala, Iraq. \\ "Correspondence to Maha Hamood Dheyauldeen (email: maha.diaaldeen12@gmail.com). \\ (Submitted: 18 December 2017 - Revised version received: 13 January 2017 - Accepted: 12 February 2017 - Published online: 26 March 2017)
}

\begin{abstract}
Objective The aim of the present study is to evaluate the urinary KIM-1 level in the patients after $24 \mathrm{~h}$ angiography as a predictive biomarker of contrast-induced acute kidney injury.

Methods This study included 80 selective patients attending in the cardiology unit (48 males, 32 females). The study was conducted in the cardiac catheterization unit at Al- Hussein Medical City/ Kerbala. Clinical examination and laboratory investigations were made before and $24 \mathrm{~h}$ after angiography, these investigations include: serum creatinine, blood urea and estimated GFR. Urinary KIM-1 was measured before and after $24 \mathrm{~h}$ angiography.

Results There was no significant difference in urinary KIM-1 when compared between CIN and non CIN group $P>0.05$. The level of urinary KIM-1 increased in the patients after $24 \mathrm{~h}$ of angiography when compared with baseline level of $P<0.001$.

Conclusion Urinary KIM-1 was not useful for predicting or detecting CIN. But urinary KIM-1 level may be useful as a biomarker for tubular damage following intravascular administration of contrast media, $24 \mathrm{~h}$.

Keywords kidney injury molecule-1, contrast-induced acute kidney injury, coronary angiography, percutaneous coronary intervention
\end{abstract}

\section{Introduction}

The administration of radiographic contrast remains an important cause of acute kidney injury in hospital, which contributes to mortality during hospitalization. ${ }^{1}$ One of the most common complications of percutaneous coronary intervention (PCI) and other type such as diagnostic procedures of the heart is contrast-induced acute kidney injury (CI-AKI). CI-AKI is defined as an increase in serum creatinine of $0.5 \mathrm{mg} / \mathrm{dL}(44 \mu \mathrm{mol} / \mathrm{L})$, or a relative $25 \%$ increase from the baseline value within $24-48 \mathrm{~h}$ following intravascular administration of contrast media. ${ }^{3}$ The incidence of CI-AKI varies widely depending on the type of angiographic procedures and the amount of contrast media. ${ }^{4}$ Using iodinated contrast also allows CI-AKI to be one of the few causes of acute kidney injury. ${ }^{5}$ The incidence of CI-AKI also depends on the baseline characteristics of the patient. Patients with normal renal function before the injection of contrast media are low (10\%). However, the incidence may increase in the patients with risk factors, such as diabetes mellitus and impaired renal function are at particular risk for the development of CI-AKI. ${ }^{6}$ There are some biomarkers serum and urinary have been recently proposed to serve as early detection of acute kidney injury after cardiac catheterization such as cystatin C, kidney injury molecule-1. ${ }^{7}$ Kidney injury molecule-1 (KIM-1) is transmembrane protein type-1. It is noted that KIM-1 was undetectable in the normal kidney. ${ }^{8}$ But it abundantly expressed in proximal tubular cells after ischemic and nephrotoxic injury. ${ }^{9}$ While its role remains unclear, it consists in a transmembrane protein whose ectodomain is shed into the urine where it can be measured..$^{10}$ It is increased in the urine in acute kidney injury and kidney transplant patients. Recently, systematic reviews had been reported that KIM-1 was an efficient novel biomarker urinary in diagnosis of acute kidney injury within period $24 \mathrm{~h}$ after a kidney injury. Urinary KIM-1 levels are associated with higher mortality risk in patients with overt kidney disease or heart failure, but there is limited evidence of an association between KIM-1 and cardiovascular mortality in the community. ${ }^{11}$ The aim of the present study to evaluate the urinary KIM-1 level in patients after $24 \mathrm{~h}$ angiography as a predictive biomarker of CI-AKI.

\section{Materials and Methods}

The study was carried out on (80) patients attending in the catheterization unit for elective coronary interventions (CAG) (48 male, 32 female) between ranges (40-81). In which the same patients were included before angiography (CAG and PCI) and after $24 \mathrm{~h}$ of angiography was conducted at Department of Biochemistry, College of Medicine, University of Kerbala and coronary catheterization unit (CCAU) in Al- Hussein Teaching Hospital / Al-Hussein Medical City, Kerbala Health Directorate / Holly Kerbala-Iraq from (Nov. 2015 to Oct 2016). The medical history of each patient was taken regarding age, gender, diabetes mellitus, type of treatment, history of renal disease, history of any other diseases, and smoking status. Measurements of their height and weight were done to calculate their body mass index (BMI), blood pressure before and during angiography.

CI-AKI was defined as an increase in serum creatinine of $0.5 \mathrm{mg} / \mathrm{dl}$ or $>25 \%$ increase from the baseline values, assessed at $24 \mathrm{~h}$ after the procedure.

The amount of contrast medium used in each patient was recorded after the procedure. All patients involved in the study were given low-osmolar non-ionic contrast media Omnipaque (Iohexol) $350 \mathrm{mg}(1 / \mathrm{ml}), 844$ Osmality (mOsm/l). Serum creatinine, serum urea and eGFR were assessed before and at $24 \mathrm{~h}$ after administration of contrast medium. Urinary KIM-1 was measured before and after $24 \mathrm{~h}$ angiography. Estimated GFR was calculated according to the modification of diet in renal disease 
(MDRD) equation: eGFR $\left(\mathrm{ml} / \mathrm{min} / 1.73 \mathrm{~m}^{2}\right)=186 \times\left(\mathrm{SCr}^{-1.154}\right) \times$ $\left(\right.$ age $\left.^{-0.203}\right) \times(0.742$ if female $) \times(1.21$ if black $) .{ }^{12}$ Urine sample was collected before and after $24 \mathrm{~h}$ operation and centrifuge 4000 (rpm), stored at $-70{ }^{\circ} \mathrm{C}$ until assayed. The urinary KIM-1 measurements were performed using sandwich enzyme-linked immunosorbent (ELISA) assays (Human KIM-1 ELISA kit, Cosabio, China). The Ethical Committees approved this study protocol are: Committees of College of Medicine, University of Karbala and Department of Medicine and committee of cardiac angiographic unit in Al- Hussein Teaching Hospital / Al-Hussein Medical City, Karbala Health Directorate / Holly Kerbela-Iraq .

\section{Statistical Analysis}

Statistical analyses were performed by using the statistical package for social sciences (SPSS) software for windows, version 21 , IBM, USA, data of 80 patients entered and analyzed. Descriptive statistics were presented as mean \pm standard deviation for continuous variables. Categorical variables were expressed as frequency (No.), and percentages (\%). Student's $t$-test was used to compare and assess the significance of differences between continuous variables. Paired $t$-test used to compare urinary KIM-1 levels between before and after operation. Chi square or Fisher exact test as appropriate test was used to assess the significance of the association between categorical variables. Receiver-operating characteristic (ROC) curves and the area under the curve (AUC) were constructed to describe the performance of serum creatinine and urinary KIM-1 at $24 \mathrm{~h}$ post-contrast media exposure. The sensitivity and specificity were calculated. The best cutoff values for biomarkers were chosen on the basis of maximum sensitivity and specificity. Probability $(P)$ value was considered significant when it is less than $0.05 \%$, and highly significant if it is less than $0.01 \%$.

\section{Results}

The study subjects included 80 patients, 48 of them were male $(60 \%)$ and 32 were female (40\%) With a mean age of $59.85 \pm 9.976$ and age range of 41-80 years. All patients underwent elective CAG or PCI. According to the presented data and to the definition CI-AKI, CI-AKI occurred in 19 patients $23.8 \%$. Fifty three patients have past history systemic hypertension whereas 27 were not hypertensive. Seventeen patients were Current smokers; and 63 patients were not. Patient's characteristics are shown in tables 1 and 2; there was significant in the type of angiography CAG/PCI in the incidence of CI-AKI. There were no significant effects for age, gender, smoking, diabetes mellitus, hypertension, statin medication and others, volume of contrast and ejection fraction in the incidence of CI-AKI.

Table 3 shows the changes in the concentrations of different biomarkers in both CIN and non CIN groups. There were significant increments in levels of SCr and eGFR after 24 h of angiography/angioplasty procedures $P<0.001,0.01$ respectively. There was no significant in urinary KIM-1 when compared between in both CIN and non CIN group $P>0.05$. Table 4 shows significant rise in urinary KIM-1 level when compared between before and after $24 \mathrm{~h}$ angiography $P<0.001$.

The result of receiver-operating characteristics (ROC) analysis $(n=80, \mathrm{CIN}=19)$ shown in the (Fig. 1$)$ showed a higher area under the curve (AUC) for serum creatinine 0.805
(95\% CI $=0.688,0.921) . P=0.000), 78.9 \%$ sensitivity and $60.7 \%$ specificity, cut off value $>1.06 \mathrm{mg} / \mathrm{dl}$. AUC of eGFR $0.739(95 \% \mathrm{CI}=0.595,0.882)$, sensitivity $=73.7 \%$ and specificity $=62.3 \%$, cut-off value $<63 \mathrm{ml} / \mathrm{kg} / 1.73 \mathrm{~m}^{2}$. AUC of urea $0.670(95 \% \mathrm{CI}=0.525,0.816)$ sensitivity $63.2 \%$ and specificity $63.9 \%$ and cut-off value $>39 \mathrm{mg} / \mathrm{dl}$. AUC of urinary KIM-1 $0.572(95 \% \mathrm{CI}=0.429,0.714) P=0.348$, cut- off value $>0.46$ $\mathrm{ng} / \mathrm{ml}$, sensitivity $52.6 \%$, specificity $50.8 \%$

\section{Discussion}

In the present study, the incidence of CIN occurred in 19 (2, diagnostic; 17 therapeutic) from 80 patients with $23.8 \%$ although all of patients have normal kidney function. The

\begin{tabular}{|c|c|c|c|c|}
\hline \multirow{3}{*}{ Characteristics } & & \multirow{2}{*}{\multicolumn{2}{|c|}{ CIN }} & \\
\hline & & & & \multirow{2}{*}{$P$-value } \\
\hline & & Negative & Positive & \\
\hline \multirow{2}{*}{$\begin{array}{l}\text { Gender } \\
\text { (male/female ) }\end{array}$} & Number & $35 / 26$ & $13 / 6$ & 0.391 \\
\hline & $\%$ & $72.9 / 81.2$ & 27.1/18.8 & \\
\hline \multirow{2}{*}{$\begin{array}{l}\text { Non-smoker/ current } \\
\text { smoker }\end{array}$} & No. & $50 / 11$ & $13 / 6$ & 0.208 \\
\hline & $\%$ & $79.4 / 64.7$ & $20.6 / 35.3$ & \\
\hline \multirow[t]{2}{*}{ Non-statins/statins } & No. & $14 / 47$ & $6 / 13$ & 0.448 \\
\hline & $\%$ & 70/78.3 & $30 / 21.7$ & \\
\hline \multirow{2}{*}{$\begin{array}{l}\text { Non- } \beta \text {-blocker/- } \\
\beta \text {-blocker }\end{array}$} & No. & $23 / 38$ & $11 / 8$ & 0.120 \\
\hline & $\%$ & $67.6 / 82.6$ & $32.4 / 17.4$ & \\
\hline \multirow{2}{*}{$\begin{array}{l}\text { Non-ACE/ACE } \\
\text { inhibitors }\end{array}$} & No & $49 / 12$ & $14 / 5$ & 0.536 \\
\hline & $\%$ & 77.8/70.6 & 22.2/29.4 & \\
\hline \multirow{2}{*}{$\begin{array}{l}\text { Angiography } \\
\text { (diagnostic/therapeutic) }\end{array}$} & No. & $25 / 36$ & $2 / 17$ & $0.014^{*}$ \\
\hline & $\%$ & $92.6 / 67.9$ & $7.4 / 32.1$ & \\
\hline
\end{tabular}

No, number; CIN: contrast-induced nephropathy; ${ }^{*}$ significant $P$ value at 0.05

\section{Table 2. Characteristics of the patients groups: with and without CIN}

\begin{tabular}{|c|c|c|c|}
\hline \multirow{2}{*}{ Characteristics } & $\mathrm{CIN}+(n=19)$ & $\mathrm{CIN}-(n=61)$ & \multirow{2}{*}{$P$-value } \\
\hline & Mean \pm SD & Mean \pm SD & \\
\hline Age (years) & $62.58 \pm 10.62$ & $59.0 \pm 9.69$ & 0.174 \\
\hline $\mathrm{BMI}\left(\mathrm{kg} / \mathrm{m}^{2}\right)$ & $27.10 \pm 3.59$ & $28.41 \pm 5.23$ & 0.421 \\
\hline $\mathrm{SBP}(\mathrm{mmHg})$ & $136.23 \pm 22.65$ & $132.79 \pm 16.84$ & 0.466 \\
\hline $\mathrm{DBP}(\mathrm{mmHg})$ & $81.05 \pm 11.49$ & $80.66 \pm 11.56$ & 0.896 \\
\hline $\mathrm{FBS}$ (mg/dl) & $197.54 \pm 68.46$ & $164.23 \pm 76.42$ & 0.094 \\
\hline $\mathrm{TC}(\mathrm{mg} / \mathrm{dl})$ & $175.64 \pm 35.09$ & $170.92 \pm 43.44$ & 0.668 \\
\hline $\mathrm{TG}(\mathrm{mg} / \mathrm{dl})$ & $165.58 \pm 56.69$ & $170.61 \pm 81.80$ & 0.804 \\
\hline VLDL-C (mg/dl) & $37.56 \pm 16.79$ & $35.43 \pm 17.09$ & 0.635 \\
\hline LDL-C (mg/dl) & $102.72 \pm 41.95$ & $101.02 \pm 38.60$ & 0.870 \\
\hline HDL-C (mg/dl) & $33.96 \pm 6.56$ & $35.94 \pm 8.46$ & 0.354 \\
\hline Volume of contrast & $265.78 \pm 111.86$ & $220.08 \pm 125.73$ & 0.160 \\
\hline $\mathrm{EF}$ & $53.47 \pm 8.07$ & $57.52 \pm 10.35$ & 0.122 \\
\hline
\end{tabular}

$\mathrm{CIN}+$, CIN positive; $\mathrm{CIN}-$, CIN negative index; SBP, systolic blood pressure; DBP, diastolic blood pressure; FBS, fasting blood sugar; EF, Ejection Fraction. 
Table 3. Changes of serum and urinary biomarkers between CIN and non CIN groups

\begin{tabular}{|c|c|c|c|}
\hline Markers & $\begin{array}{c}\text { CIN }+N=(19) \\
\text { Mean } \pm \text { SD }\end{array}$ & $\begin{array}{c}\text { CIN }-N=(61) \\
\text { Mean } \pm \text { SD }\end{array}$ & $P$-value \\
\hline \multicolumn{4}{|c|}{ S. Urea (mg/dl) } \\
\hline At $0 \mathrm{~h}$ & $36.54 \pm 12.91$ & $31.64 \pm 7.03$ & $0.036^{*}$ \\
\hline After $24 \mathrm{~h}$ & $50.20 \pm 25.06$ & $39.20 \pm 13.23$ & $0.015^{*}$ \\
\hline \multicolumn{4}{|c|}{ S. Creatinine (mg/dl) } \\
\hline At $0 \mathrm{~h}$ & $0.77 \pm 0.22$ & $0.88 \pm 0.18$ & $0.037^{*}$ \\
\hline After $24 \mathrm{~h}$ & $1.30 \pm 0.29$ & $0.98 \pm 0.19$ & $0.000^{* * *}$ \\
\hline \multicolumn{4}{|l|}{ eGFR } \\
\hline At $0 \mathrm{~h}$ & $102.47 \pm 43.04$ & $82.52 \pm 19.94$ & $0.006^{* *}$ \\
\hline After $24 \mathrm{~h}$ & $56.57 \pm 18.42$ & $72.11 \pm 15.89$ & $0.001^{* *}$ \\
\hline \multicolumn{4}{|c|}{ U. KIM-1 (ng/ml) } \\
\hline At $0 \mathrm{~h}$ & $0.36 \pm 0.42$ & $0.36 \pm 0.31$ & 0.962 \\
\hline After $24 \mathrm{~h}$ & $0.81 \pm 0.71$ & $0.72 \pm 0.79$ & 0.645 \\
\hline
\end{tabular}

$\mathrm{S}$, serum; eGFR, glomerular filtration rate; $\mathrm{U}$, urinary; KIM-1, kidney injury molecule-1.

Table 4. Change in serum and urinary levels of biomarkers between pre-post angiography

\begin{tabular}{lccc}
\hline Biomarkers & Pre & Post 1-day & P-value \\
\hline S.Urea $(\mathrm{mg} / \mathrm{dl})$ & $32.80 \pm 8.94$ & $41.81 \pm 17.32$ & $0.000^{* * *}$ \\
$\begin{array}{l}\text { S.Creatinine } \\
\text { (mg/dl) }\end{array}$ & $0.85 \pm 0.19$ & $1.06 \pm 0.25$ & $0.000^{* * *}$ \\
eGFR & $87.26 \pm 28.23$ & $68.42 \pm 17.70$ & $0.000^{* * *}$ \\
U. KIM-1 (ng/ml) & $0.36 \pm 0.34$ & $0.74 \pm 0.77$ & $0.000^{* * *}$
\end{tabular}

S, serum; U, urinary; KIM-1, kidney injury molecule-1; eGFR, glomerular filtration rate.

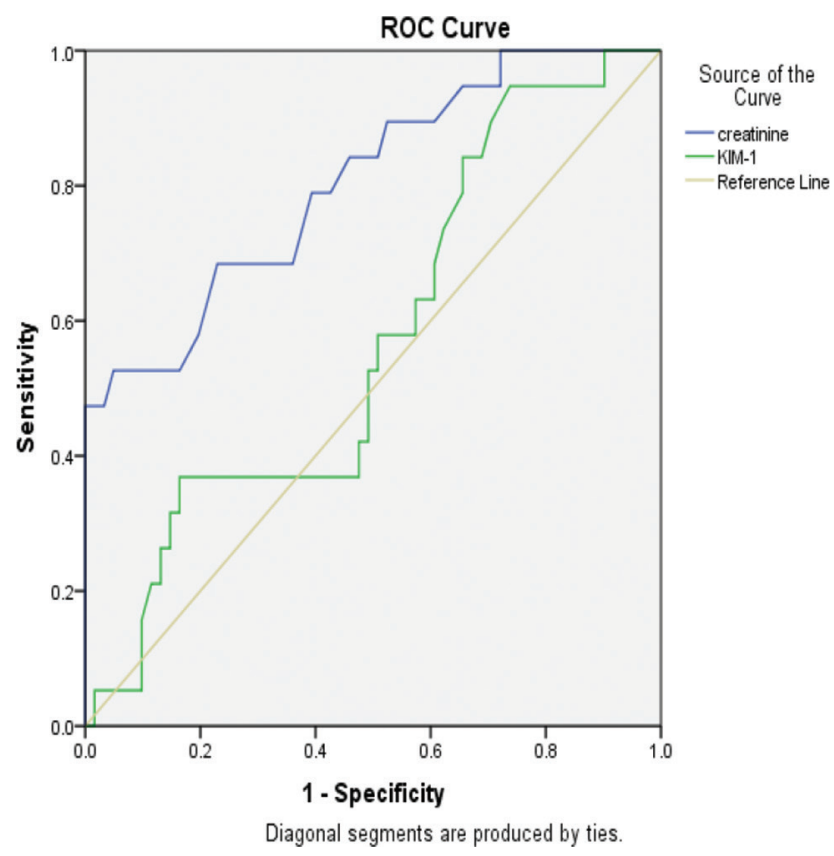

Fig. 1 ROC of serum and urinary biomarkers after $24 \mathrm{~h}$ angiography. AUC for serum creatinine $0.805(95 \% \mathrm{Cl}=0.688$, $0.921), 78.9 \%$ sensitivity and $60.7 \%$ specificity, cut off value $>1.06$ $\mathrm{mg} / \mathrm{dl}$. AUC of urinary KIM-1 0.572 , cut- off value $>0.46 \mathrm{ng} / \mathrm{ml}$, sensitivity $52.6 \%$, specificity $50.8 \%$. results in the present study showed even patients with normal kidney function have the development of CI-AKI after exposure to contrast media; this finding is agreed with Assareh et al. ${ }^{13}$ Recent study carried by Sato et al., showed that CIN was an independent predictor of subsequent renal events in the patients who underwent cardiac catheterization. ${ }^{14}$ The risk of CI-AKI due to coronary angiography increases dramatically with low kidney function. ${ }^{15}$

The present study shows that urinary KIM-1 level was elevated at the $24 \mathrm{~h}$ of cardiac catheterization. There was a statistically significant rise in the urinary level KIM- $P<0.001$ in patients when compared level concentration between preand post-operation. This result may be referred to proximal tubular injury by contrast medium, although the classical marker KIM-1 was not significant when compared between positive and negative CIN $P>0.05$. Therefore, urinary KIM-1 was not useful for predicting or detecting CIN.

These results are due to tubular kidney damage, where very high concentrations appeared in some patients of different conditions may cause tubular damage including diabetes, infections, surgery, heart failure and treatments with nephrotoxic agents of contrast media. ${ }^{16}$ Measurement of urinary biomarkers has the potential to determine the risk of renal damage that may raise the level of urinary at $24 \mathrm{~h}$ after exposure contrast media. This could provide a basis for using urinary KIM-1 level in clinical practice. There are some studies used urinary KIM-1 level for early diagnosis CIN as Akdeniz et al. found that at 6th and 48th hour of contrast exposure found that KIM-1 levels increased in the patients with CIN ( $P$ $<0.01$; median levels, 0.27 and $0.70 \mathrm{mg} / \mathrm{dl}) .{ }^{17}$ Another report by Malyszko et al. found no data in the literature on such time course changes of KIM-1in contrast nephropathy as in our study. ${ }^{18}$ Another work carried by Kooiman et al. urinary KIM-1 excretion was unaffected by CE-CT both in patients with and without CI-AKI, suggesting that CI-AKI was not accompanied by tubular injury. ${ }^{19}$

Urinary KIM-1 is a more recently described type 1 cell membrane glycoprotein that is expressed in humans when the injured renal proximal tubule of the kidney, KIM-1 not detectable in the normal kidney but expresses in proximal tubular cells after ischemic and nephrotoxic injury. ${ }^{20}$ This may increase levels urinary after $24 \mathrm{~h}$ without any change before exposure of contrast media. Perhaps some of our patients had conducted two operations during a shorter time and take two doses of contrast media. Effects of contrast media on the kidney are known to induce damage of endothelial cells by direct cytotoxicity or the viscosity of the contrast media and perhaps lead to the development of renal hypoxia. ${ }^{21}$ This will expose their kidneys to a double risk that may explain the transient proximal tubular damage by contrast medium. The increase of the ectodomain sheds from cells into the urine shortly after proximal tubular kidney injury allows KIM-1 to serve as an early sensitive urinary biomarker in kidney injury detection. ${ }^{22}$ Therefore urinary excretion of KIM-1 may be clinically recognized as a useful biomarker of renal injury after angiography.

ROC analysis shows a higher AUC for SCr 0.805 (95\% CI = $0.688,0.921)$ sensitivity $=78.9 \%$ and $60.7 \%=$ specificity, than urinary KIM $0.572(95 \% \mathrm{CI}=0.429,0.714) P=0.348$, cut-off value $>0.46 \mathrm{ng} / \mathrm{ml}$, sensitivity $52.6 \%$, specificity $50.8 \%$. These findings refer to serum creatinine better than urinary KIM- 1 in early detection of CI-AKI. 
In the present study, serum creatinine is still the standard marker for detecting temporal changes of renal function in individuals with established renal disease. Creatinine is the use of a sign inexpensive to measure kidney function when compared with other recent marker, which is available in all laboratories and can be easily measured in comparison with other vital signs.

\section{Conclusion}

Urinary KIM-1 was not useful for predicting early CI-AKI. Urinary KIM-1 was only useful biomarker of tubular damage caused by contrast medium after $24 \mathrm{~h}$ CAG and PCI.

\section{Acknowledgments}

Great thanks are due to all members of the medical staff of catheterization unit in the cardiological center in ALHussein Teaching Hospital/Al-Hussein medical city. Also I want to thank Dr. Mohammed Mahdi and all members of medical staff of laboratory unit in AL-Hussein Teaching Hospital.

\section{Conflict of Interest}

None

\section{References}

1. Tanaga K, Tarao K, Nakamura Y, Inoue T, Jo K, Ishikawa T, et al. Percutaneous coronary intervention causes increase of serum cystatin C concentration even in the patients with a low risk of contrast-induced nephropathy. Cardiovasc Interv Ther. 2012;27:168-173.

2. Brown JR, Rezaee ME, Nichols EL, Marshall EJ, Siew ED, Matheny ME. Incidence and in-hospital mortality of Acute Kidney Injury (AKI) and dialysis-requiring AKI (AKI-D) after cardiac catheterization in the national inpatient sample. J Am Heart Assoc. 2016;5:e002739.

3. Cely CM, Schein RM, Quartin AA. Risk of contrast induced nephropathy in the critically ill: a prospective, case matched study. Critical Care. 2012;16:1.

4. Malyszko J, Bachorzewska-Gajewska H, Poniatowski B, Malyszko JS, Dobrzycki S. Urinary and serum biomarkers after cardiac catheterization in diabetic patients with stable angina and without severe chronic kidney disease. Renal Failure. 2009:31:910-919.

5. Parfrey P. The clinical epidemiology of contrast-induced nephropathy Cardiovasc Interv Radiol. 2005;28:S3-11.

6. Palevsky PM. Defining contrast-induced nephropathy. Clin J Am Soc Nephrol. 2009;4:1151-1153.

7. Morcos SK. Prevention of contrast media-induced nephrotoxicity after angiographic procedures. J Vasc Interv Radiol. 2005;6:13-23.

8. Hojs R, Ekart R, Bevc S, Hojs N. Biomarkers of Renal disease and progression in patients with diabetes. J Clin Med. 2015;4:1010-1024.

9. Devarajan P. Biomarkers for the early detection of acute kidney injury. Curr Opin Pediat. 2011;23:194.

10. Vaidya VS, Ferguson MA, Bonventre JV. Biomarkers of acute kidney injury. Ann Rev Pharmacol Toxicol. 2008;48:463.

11. Carlsson AC, Larsson A, Helmersson-Karlqvist J, Lind L, Ingelsson E, Larsson $\mathrm{TE}$, et al. Urinary kidney injury molecule-1 and the risk of cardiovascular mortality in elderly men. Clin J Am Soc Nephrol. 2014;CJN-11901113.

12. Levey AS, Stevens LA, Schmid CH, Zhang YL, Castro AF, Feldman HI, et al. A new equation to estimate glomerular filtration rate. Ann Intern Med. 2009;150:604-612

13. Assareh A, Yazdankhah S, Majidi S, Nasehi N, Mousavi SS. Contrast induced nephropathy among patients with normal renal function undergoing coronary angiography. J Renal Inj Prev. 2016;5:21.

14. Sato A, Aonuma K, Watanabe M, Hirayama A, Tamaki N, Tsutsui H, et al. Association of contrast-induced nephropathy with risk of adverse clinical outcomes in patients with cardiac catheterization: From the CINC-J study. International Journal of Cardiology. 2017 Jan. 15;227:424-9.

15. Stacul F, van der Molen AJ, Reimer P, Webb JA, Thomsen HS, Morcos SK, et al. Contrast-induced nephropathy: updated ESUR contrast media safety committee guidelines. Eur Radiol. 2011:21:2527-2541.

16. Helmersson-Karlqvist J, Ärnlöv J, Carlsson AC, Lind L, Larsson A. Urinary KIM-1, but not urinary cystatin C, should be corrected for urinary creatinine. Clin Biochem. 2016;49:1164-1166.

17. Akdeniz D, Celik HT, Kazanci F, Yilmaz H, Yalcin S, Bilgic MA, et al. Is kidney injury molecule 1 a valuable tool for the early diagnosis of contrast-induced nephropathy? J Invest Med. 2015;63:930-934.

18. Malyszko J, Bachorzewska-Gajewska H, Poniatowski B, Malyszko JS, Dobrzycki S. Urinary and serum biomarkers after cardiac catheterization in diabetic patients with stable angina and without severe chronic kidney disease. Renal Failure. 2009;31:910-919.

19. Kooiman J, Pasha SM, Zondag W, Sijpkens YW, van der Molen AJ, Huisman $M V$, et al. Meta-analysis: serum creatinine changes following contrast enhanced CT imaging. Eur J Radiol. 2012;81:2554-2561.

20. Perico N, Cattaneo D, Remuzzi G. Kidney injury molecule 1: in search of biomarkers of chronic tubulointerstitial damage and disease progression. Am J Kidney Dis. 2009;53:1-4.

21. Kwok CS, Pang CL, Yeong JK, Loke YK. Measures used to treat contrast-induced nephropathy: overview of reviews. Br J Radiol. 2013;86:20120272.

22. Huang Y, Craig Don-Wauchope A. The clinical utility of kidney injury molecule 1 in the prediction, diagnosis and prognosis of acute kidney injury: a systematic review. Inflam Allergy Drug Targets. 2011;10:260-271.

This work is licensed under a Creative Commons Attribution-NonCommercial 3.0 Unported License which allows users to read, copy, distribute and make derivative works for non-commercial purposes from the material, as long as the author of the original work is cited properly. 